\title{
T.C. Hsu: In memory of a rare scientist
}

\section{April 17, 1917 - July 9, 2003}

\section{S. Pathak}

Department of Molecular Genetics, The University of Texas, M.D. Anderson Cancer Center, Houston, Texas (USA)

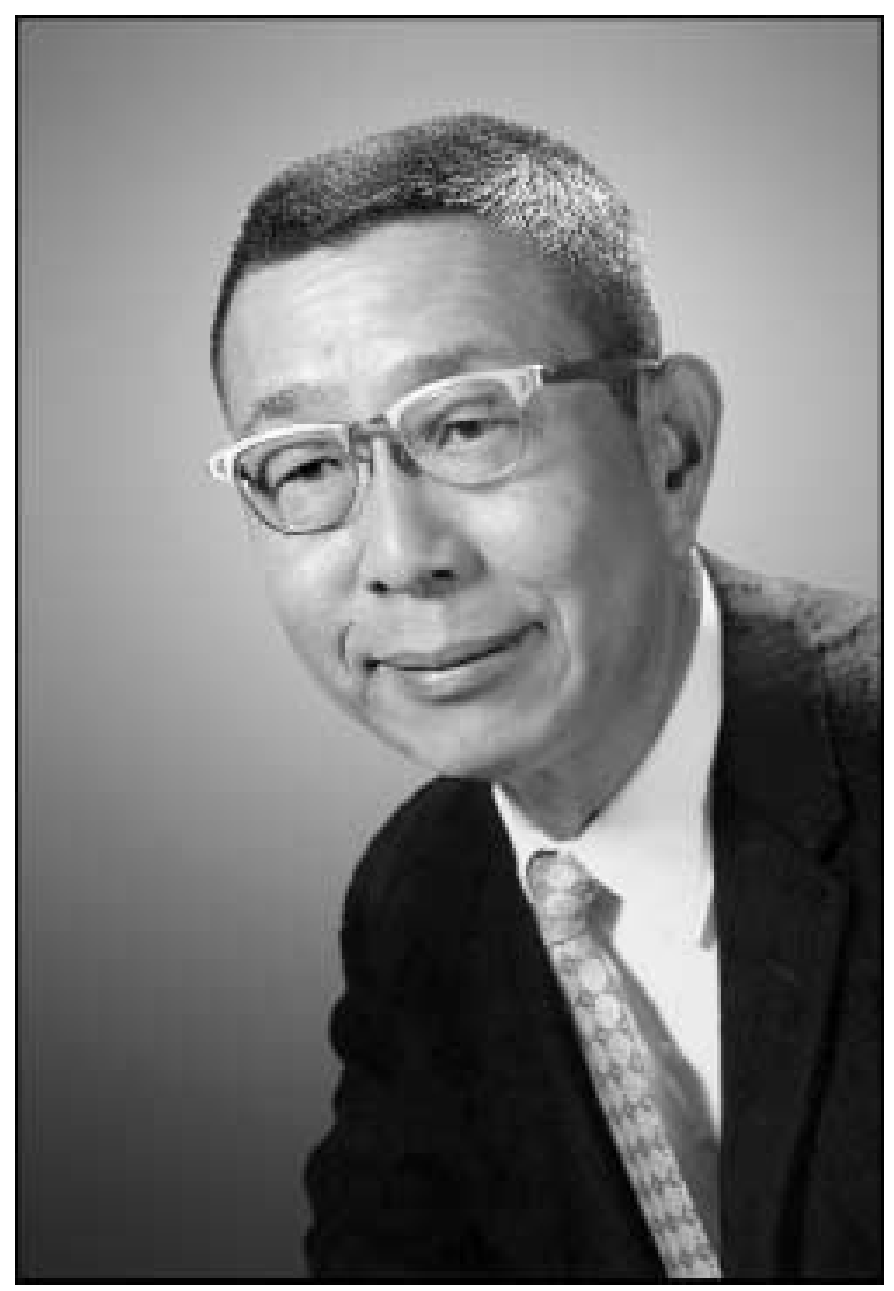

I consider myself immensely fortunate to have been associated for more than 31 years with a rare scientist, Tao-Chiuh Hsu, affectionately called "T.C." by many of his colleagues. He not only inspired me to study mammalian cytogenetics, but he also taught me many things that one must know to "survive" in the scientific community. T.C. Hsu was a great scientific builder, a scholar with multiple talents, a lover of nature, and a true and remarkable individual with many virtues. All of these qual- 
ities made him a "rare scientist" who was loved and admired by many. T. C. Hsu died on July 9, 2003, in Houston, Texas, at the age of 86 after a brief illness. He is survived by his daughter, Margaret Hsu. Mrs. Jeanette Doo Hsu died on December 18, 2003 in Houston at the age of 83.

T.C. Hsu was born on April 17, 1917, in a village near the mountain range of Shaohsing, in Chekiang Province, China. His family moved frequently from city to city during his early childhood because of his father's occupation, a chief engineer of the North China River Commission. From the age of 13 (1930), T.C. Hsu lived in the dormitory of Hangchow School where he also learned to be independent. After completing his undergraduate studies in China, with the help of his teacher, C.C. Tan, a former student of Professor Th. Dobzhansky, T.C. Hsu sailed from Shanghai to Texas in 1948. Upon arrival, he enrolled at The University of Texas at Austin to pursue a Ph.D. under the mentorship of Professor J.T. Patterson. Dr. Hsu's work on the mapping of salivary gland chromosomes of Drosophila virilis is still considered a landmark in the field. While in Austin, he met Professor M.J.D. White, who was studying the chromosomes of grasshoppers. During his field work on insect collection, Hsu collected Drosophila for his research, and in his spare time, he helped Professor White to collect live grasshoppers.

After receiving his Ph.D. degree in 1951, Hsu accepted a postdoctoral position in the laboratory of Charles Marc Pomerat, a famous tissue culturist at The University of Texas Medical Branch (UTMB) in Galveston, Texas. Although trained in Drosophila genetics, T.C. Hsu had no choice but to make tremendous efforts to learn about human tissue culture. He was fascinated, however, to watch the time-lapse movies of cell activities in cultures that had been introduced to him by Professor Pomerat. His first year in Galveston was most rewarding. Hsu accidentally discovered the magic hypotonic solution pre-treatment method for spreading cumbersome human chromosomes, which revolutionized the field of mammalian and human cytogenetics. His famous paper on the spreading technique of human chromosomes was published in The Journal of Heredity in 1952. The laboratory where T.C. Hsu discovered this technique was referred to as "The Mad House" because the tissue culture laboratory at UTMB-Galveston was located in the Texas State Psychiatric Hospital.

In 1955, Hsu joined the faculty of The University of Texas M.D. Anderson Hospital and Tumor Institute (now known as the M.D. Anderson Cancer Center) in Houston to start his own laboratory. He remained there until his death. I was first introduced to him in 1964 in absentia through the Mammalian Chromosomes Newsletter (MCN), which he edited and published from Houston. As a Ph.D. student in the Zoology Department of Banaras Hindu University, Varanasi, India, I read his "Dear Colleagues" column in MCN, and the experience was a turning point in my life, influencing me to work on mammalian chromosomes. In 1970, after receiving a Welch Foundation Postdoctoral Fellowship, I began working at the Baylor College of Medicine in Houston and finally met T.C. Hsu across the street at M.D. Anderson. My first meeting with him impressed me immensely because he spent almost three hours showing me his laboratory, which included a micropho- tograph of a Texas-sized sperm that was hanging in the Electron Microscope Laboratory of Bill R. Brinkley. (This was also my first meeting with William R. Brinkley, who would also become one of two most admired colleagues of T.C. Hsu). Brinkley and Hsu were among the first investigators to develop experimental approaches to electron microscopy.

I joined Hsu's laboratory on May 10, 1972, and was given 11 live animals belonging to the genus Tylomys (climbing rat) to study their chromosomes using the newly developed Giemsa (G)- banding technique. This was the beginning of an exciting period of mammalian chromosome banding. His laboratory had just discovered the C-banding technique to demonstrate constitutive heterochromatin in human, Drosophila, and several other mammalian species. My very first project in Hsu's laboratory was to study the cytotaxonomy of the Tylomys group. With great effort and difficulty, I not only characterized their chromosomes by G- and C- banding, but I also identified three hybrid animals in them which were previously unknown. After my discovery of the banding homology of these specimens, the supplier was contacted and he later confirmed the three hybrid animals that I had identified by G-banding (Chromosoma, 42:215-228, 1973). Because of this first observation, Hsu offered me a position in his laboratory, and the rest is history. In addition to our scientific collaborations, we formed a personal friendship, and on numerous occasions, he confided in me about his early and present life, his viewpoints on various subjects, including rebirth, and his sentiments on numerous issues, some of which he had never previously revealed to anyone.

In the early 1970s, Hsu's laboratory was frequently visited by numerous renowned scientists, some unknown scholars, and by pre- and postdoctoral fellows from around the world. I personally enjoyed those early days of mammalian cytogenetics, but we soon discovered that we had to focus our research on cancer cytogenetics. In addition, T.C. Hsu devoted his time to teach, discipline, and encourage the many mammalian and human cytogeneticists who came from 36 countries around the world to learn from him. He was a born teacher and an intellectual pollinator. Students and audiences alike were hypnotized by his oral presentations, considering him a gifted speaker. Hsu was also a great storyteller who held his audience captive. $\mathrm{He}$ loved telling stories and I was his greatest listener of all who were privileged to hear his tales. In addition, T.C. Hsu was a great mentor, showman, naturalist and, above all, a great human being. He was always ready to help others, not only with scientific matters, but also as a handyman. He would never refuse anyone who asked for his help, no matter how busy his laboratory schedule was. In addition, Hsu always discussed his research ideas freely and was generous in sharing his knowledge with others. Many times, others "scooped" his ideas and used them before he had time to perform the experiments himself and without giving him the proper credit, after which he would say, "So let them steal my ideas. I will generate some more."

T.C. Hsu had frozen fibroblast cultures of mammalian species ranging from Aardvark to Zebra (A to Z) that I inherited from him in 1986 after his first retirement. In 1971, Time magazine published an article on "Dr. T.C. Hsu and his Frozen Zoo", which detailed his foresight that the cloning of endan- 
gered or extinct mammalian species from their frozen fibroblasts might be a future reality. In addition, throughout his career, he was the recipient of numerous honors and awards, including the coveted Ernst W. Bertner Memorial Award for distinguished contributions in cancer research. He was also the first in-house Professor appointed to the Olga Keith Weiss Chair in Cancer Research at the M.D. Anderson Cancer Center.

Although T.C. Hsu officially retired in 1986, he was appointed a Professor emeritus and never stopped working. He reported to the Cellular Genetics Laboratory every day and regularly asked me his favorite question, "Sen, what is the discovery of the week?" He enjoyed teaching and performing microscopy, but even more, he loved to learn new things in the field of telomere dynamics. He also liked to write books and articles for scientific journals. His book, Human and Mammalian Cytogenetics: A Historical Perspective, published in 1979, is a classic, but he was just as proud of his last article that we published together in 2001 (Chromosoma, 110:214-220) with Asha S. Multani on the heterochromatin and telomere DNA homology. To all visitors to his laboratory, he would proudly show the col- ored microphotographs of fluorescence in situ hybridization (FISH) preparations of telomeres in several mammalian species. His life was his laboratory where he enjoyed playing with beautiful chromosomes of not only cancer cells but of many mammalian species. Hsu also knew the art of planting seeds of scientific pursuits in the minds of his associates and students. I personally feel very fortunate to have had the opportunity to work in his laboratory where I met the most famous cytogeneticists in the world including M.J.D. White, A. Levan, P.C. Nowell, T. Caspersson, F. Mitelman, A. Gropp, J. German, C.E. Ford, E.H.Y. Chu, K. Benirschke, A.T. Natarajan, and S. Ohno, among many others.

T.C. Hsu died on July 9, 2003, and left us a rich legacy of scientific pursuits and achievements in the field of cytogenetics. He will forever be known as "The Father of Mammalian Cytogenetics," and we in the scientific community feel the deep void left by his passing. He was my mentor and my friend for more than three decades, and I shall miss him most of all. I am honored and blessed to have known him, and I shall carry the memory of this "Rare Scientist" with me in my work and in my heart for the rest of my life. 